\title{
A study of incidence of pulmonary tuberculosis in chronic asthmatic patients
}

\author{
Adchitre Hitesh Ramesh ${ }^{1}$, D B More ${ }^{2 *}$, Megha Jaraje ${ }^{3}$
}

${ }^{1}$ Post Associate Professor, Department of Microbiology $\left\{{ }^{2}\right.$ Associate Professor, Department of Chest $\}$ \{ ${ }^{3}$ Medical Officer, RNTCP $\}$

SBH Government Medical College, Dhule, Maharashtra, INDIA.

Email: dbmore62@gmail.com

Abstract Background: Chronic obstructive pulmonary disease (COPD) and tuberculosis (TB) are two important causes of mortality and morbidity in our country. Asthma is most commonly observed COPD in the developing countries. Aim and objective: To study the incidence of Pulmonary Tuberculosis in chronic Asthmatic patients at a tertiary health care centre Methodology: Present study was a prospective study carried out on 150 asthmatic patients who were taking treatment for more than 5 years. Data was collected with pre tested questionnaire. Data included demographic data, clinical history and clinical examination. All the patients were subjected to chest x-ray, sputum examination for acid fast bacilli by Zeil nelson

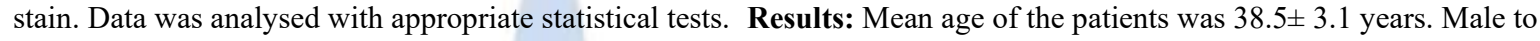
female ratio was $1.73: 1$. Majority of the patients (40.67\%) belonged to lower middle class followed by upper lower class (28\%). The incidence of pulmonary tuberculosis in our study was $4 \%$. Patients with smoking habits, use of steroids developed pulmonary tuberculosis.

Key Word: pulmonary tuberculosis.

\section{*Address for Correspondence:}

Dr D B More, Asspciate Professor, Department of Chest, SBH Government Medical College, Dhule, Maharashtra, INDIA.

Email: dbmore62@gmail.com

Received Date: 06/12/2019 Revised Date: 10/01/2020

DOI: https://doi.org/10.26611/10081611

This work is licensed under a Creative Commons Attribution-NonCommercial 4.0 International License. (cc) EY-NC

\begin{tabular}{|l|l|}
\hline \multicolumn{2}{|c|}{ Access this article online } \\
\hline Quick Response Code: & Website: \\
& www.medpulse.in \\
\cline { 2 - 2 } & \\
\hline
\end{tabular}

\section{INTRODUCTION}

Respiratory disorders like asthma, Bronchitis, Tuberculosis and pneumonia are major burden of disease in India. These diseases are mainly attributed with exposure to indoor pollution, solid-cooking fuels, poor housing, low nutritional status and sanitary conditions. The association of respiratory disorders with geographical region may be relevant with population density, industrial and textile pollutants, and tobacco consumption. ${ }^{1}$ India has the highest TB burden in the world accounting for $27 \%$ of the global cases with an estimated incidence of 2.74 million. ${ }^{2}$ India is the highest TB burden country in the world and hence is likely to harbor significant burden of TB-associated COPD. India has a growing population of COPD and is in second place for harboring the most number of morbidity and mortality cases from obstructive airway disease, after China. ${ }^{3}$ Various predisposing factors for tuberculosis include malnutrition, overcrowding, alcoholism, smoking and immune compromised states. Chronic obstructive pulmonary disease (COPD) affects 65 million people worldwide and is the third leading cause of death. Among these deaths, $90 \%$ deaths are in low- and middle-income countries which has maximum number of pulmonary tuberculosis (TB). The interrelationship between TB and COPD is very complex. A substantial number of TB patients develop post tubercular airway disease or TB-associated COPD. ${ }^{4-7}$ Various studies were done in relation to TB and COPD. Different associations were published regarding $\mathrm{TB}$ and COPD. COPD is a common comorbidity in patients with TB. Patients with history of tuberculosis have increased frequency of exacerbations of COPD. COPD patients are also at high risk of developing pulmonary TB. COPD influences the clinical presentation of TB and is a risk factor for increased 
morbidity and mortality from TB..$^{8-15}$ The use of steroids, physical and mental stress and poor socio economic status because of loss of wages due to asthma may predispose the patient to tuberculosis. Tobacco smoking is a major aetiological factor in the development of COPD. Several early studies supported an association between tobacco smoking and the tendency to develop TB. Use of steroids is also associated with development of TB in these patients due to immunosuppression. In asthmatic patients due to chronicity changes in the mucosa and lining epitheliam is often present. They are more prone to secondary bacterial infection which lead to exacerbation of asthmatic attacks. They are frequently treated with steroids and antibiotics this causes immunosuppression. Usually they respond to antibiotics but if they do not respond then sputum culture is advised and as per antibiotic sensitivity pattern antibiotics were given still if the patient doesn't respond then other possibilities were taken into consideration. Most of the studies were carried out on TB associated COPD and patients developing COPD who are having tuberculosis. Very few studies have seen the development of tuberculosis in COPD patients. Asthma is most commonly prevalent COPD in our country so present study was aimed at finding incidence of tuberculosis in chronic asthmatic patients at a tertiary health care centre.

\section{MATERIAL AND METHODS}

Present study was a prospective study carried out at tertiary health care centre. Study population was 150 asthmatic patients who were taking treatment for more than 5 years. Inclusion criteria: 1. Patients with history of asthma for more than five years and taking treatment

Exclusion criteria: 1. Patients with history of asthma less than 5 years 2 . Patients not willing to participate in the study.

Study was approved by ethical committee of the institute. A valid written consent was taken from the patients after explaining study to them.

Data was collected with pre tested questionnaire. Data included demographic data like age, sex and occupation. Detailed clinical history was taken from the patients. Clinical history related to duration of asthma, treatment taking for asthma, frequency of asthmatic attacks, past history of tuberculosis, family history of asthma was noted. A through clinical examination of the patients was done. All these patients were treated with antihistaminics steroids, antibiotics bronchodilators meter dose inhaler pumps on and off frequently. Routine investigations like complete blood count, renal and liver function tests were done. ESR is the main haematological investigation done but is found to be inconclusive as the patients are treated with steroids. All the patients were subjected to chest xray, sputum examination for acidfast bacilli by zeil nelson stain. Data was subjected to statistical analysis using
Statistical package for social sciences (SPSS v 21.0, IBM). Descriptive statistics like frequencies and percentage for categorical data, Mean and SD for numerical data has been depicted.

\section{RESULTS}

Table 1 shows distribution of patients according to age group. Majority of the patients were from the age group of $31-40$ years $(30 \%)$ followed by $41-50$ years $(20.67 \%)$. Patients in the age group of 51-60 were $18.67 \%$. 18-30 years age group patients contributed $17.33 \%$. Patients above 60 years were $13.33 \%$. Mean age of the patients was $38.5 \pm 3.1$ years.

Majority of the patients in our study were males $95(63.33 \%)$. Female population in our study was 55 $(36.67 \%)$. Male to female ratio was 1.73:1. Socioeconomic status of the patient was determined by using Kuppuswamy scale of socioeconomic status. Majority of the patients $(40.67 \%)$ belonged to lower middle class followed by upper lower class $(28 \%)$. Patients in upper middle class were $14 \%$. Patients in extremes of the class I.e upper class and lower lower class were $2 \%$ and $15.33 \%$ respectively. (table 2) In our study out of 150 patients 130 patients were outside workers and 20 females were housewife. In our study, we enquired about the smoking habit in the patients. Out of 150 patients, $80(53.33 \%)$ were non smokers. Current smokers were $40(26.67 \%) .20 \%$ of the patients have stopped smoking. Duration of smoking in current smoker ranges from 1-23 years. (table 3) All patients were treated with antihistaminics, steroids, antibiotics bronchodilators meter dose inhaler pumps on and off frequently. Majority of the patients used inhaled steroids 60(40\%) followed by bronchodilators $48(32 \%)$. Pulmonary function test were done in 150 patients and results were in favour of obstructive lung pathology. All the patients were subjected to chest $\mathrm{x}$-ray, sputum examination for acidfast bacilli by Zeil nelson stain. Fig 2 shows incidence of pulmonary tuberculosis in patients with chronic asthma (duration more than 5 years). Out of total 150 patients 6 patients were found positive for acidfast bacilli on ZN stain. Only TWO X-ray were suspecting koch's out of 150 patients. Thus the incidence of pulmonary tuberculosis in our study was $4 \%$. Among the positive patients one was female and 5 were male. Regarding the smoking habits, the female was non smoker. Among the remaining 5 patients 4 were current smokers with duration of smoking ranging from 2-17 years. One patient was past smoker, he left smoking 3 years back. Among the positive patients all were using inhaled steroids. Mean duration of use of inhaled steroid was $9.41 \pm$ 2.7 years. Due to unavailability of AFB culture facility and Gene expert study we were not able to talk about MDR cases in this study. 
Table 1: Distribution of patients of chronic asthma according to age group

\begin{tabular}{cccc}
\hline Sr no & Age group (years) & No of patients & Percentage \\
\hline 1 & $18-30$ & 26 & $17.33 \%$ \\
2 & $31-40$ & 45 & $30 \%$ \\
3 & $41-50$ & 31 & $20.67 \%$ \\
4 & $51-60$ & 28 & $18.67 \%$ \\
5 & $>60$ & 20 & $13.33 \%$ \\
\hline & Total & 150 & $100 \%$ \\
\hline
\end{tabular}

Table 2: Distribution of patients of chronic asthma according to Socioeconomic status

\begin{tabular}{|c|c|c|c|}
\hline Sr no & Socioeconomic class & No of patients & Percentage \\
\hline 1 & Upper & 03 & $2 \%$ \\
\hline 2 & Upper Middle & 21 & $14 \%$ \\
\hline 3 & Lower Middle & 61 & $40.67 \%$ \\
\hline 4 & Upper Lower & 42 & $28 \%$ \\
\hline \multirow[t]{2}{*}{5} & Lower Lower & 23 & $15.33 \%$ \\
\hline & Total & 150 & $100 \%$ \\
\hline \multicolumn{4}{|l|}{$70.00 \%$} \\
\hline \multicolumn{4}{|l|}{$60.00 \%$} \\
\hline \multicolumn{4}{|l|}{$50.00 \%$} \\
\hline \multicolumn{4}{|l|}{$40.00 \%$} \\
\hline \multicolumn{4}{|l|}{$30.00 \%$} \\
\hline \multicolumn{4}{|l|}{$20.00 \%$} \\
\hline \multicolumn{4}{|l|}{$10.00 \%$} \\
\hline $0.00 \%$ & Male & Fem & \\
\hline
\end{tabular}

Figure 1: Distribution of patients of chronic asthma according to sex

Table 3: Distribution of patients of chronic asthma according to smoking habits

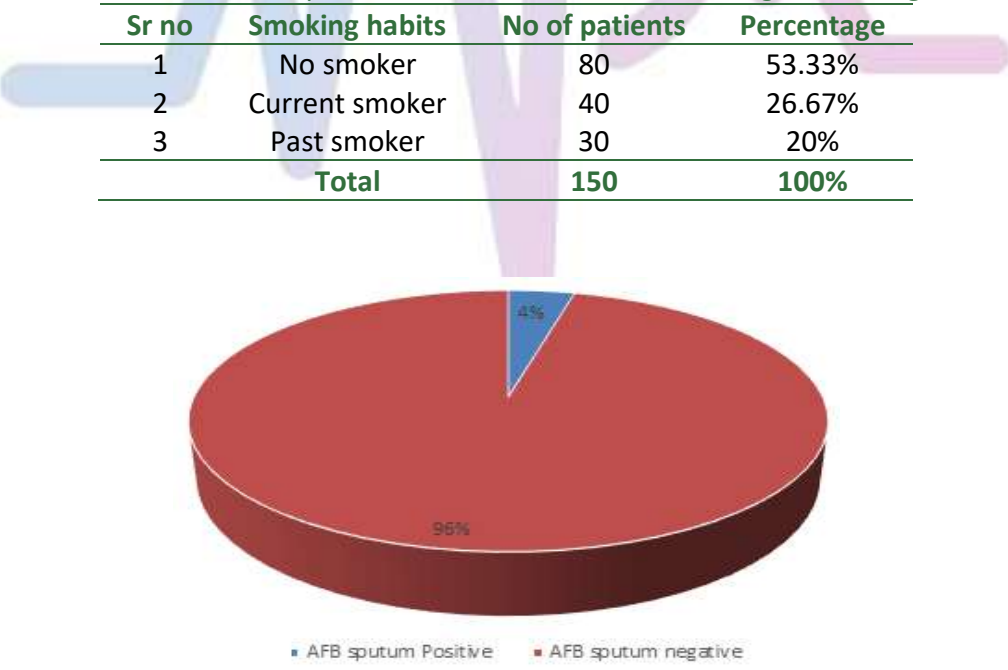

Figure 2: Incidence of pulmonary tuberculosis in patients with chronic asthma

\section{DISCUSSION}

In our study, Majority of the patients were from the age group of 31-40 years (30\%) followed by $41-50$ years $(20.67 \%)$. Mean age of the patients was $38.5 \pm 3.1$ years. Similar to our study, Lee et al. observed the mean age of the COPD cases as $54.5 \pm 22.9$ years. ${ }^{8}$ Majority of the patients in our study were males $95(63.33 \%)$. Female population in our study was $55(36.67 \%)$. Male to female ratio was 1.73:1. Similar to our study Lee et al. observed a male-female ratio of $1.6: 1 .^{8}$

We found that, majority of the patients $(40.67 \%)$ belonged to lower middle class followed by upper lower class (28\%). The relationships between socio-economic status and respiratory diseases like COPD, tuberculosis is proved in previous studies. ${ }^{16}$ Out of total 150 patients 6 patients were 
found positive for acidfast bacilli on $\mathrm{ZN}$ stain. Thus the incidence of pulmonary tuberculosis in our study was $4 \%$. In a study by Popescu et al., where in $90 \%$ of the patients, bronchial asthma developed after tuberculosis and $10 \%$ patients presented with bronchial asthma and subsequently developed pulmonary TB. ${ }^{17}$ In our study, Out of 150 patients, 80(53.33\%) were non smokers. Current smokers were $40(26.67 \%) .20 \%$ of the patients have stopped smoking. Duration of smoking in current smoker ranges from 1-23 years. Among the positive patients 4 were current smokers with duration of smoking ranging from 217 years. One patient was past smoker. Cigarette smoking also increases the risk of developing TB by $3-5$ folds. ${ }^{18-19}$ Smoking suppresses the innate and adaptive immune response with decreased levels of pro-inflammatory cytokines and circulating immunoglobulins and reduces the activity of alveolar macrophages, dendritic cells, and natural killer cells. ${ }^{20-21}$ Majority of the patients used inhaled steroids $60(40 \%)$ followed by bronchodilators 48 $(32 \%)$. Among the positive patients all were using inhaled steroids. Mean duration of use of inhaled steroid was $9.41 \pm$ 2.7 years. In a study on patients with inhaled corticosteroids researches observed that Multivariate Cox regression showed ICS use was an independent risk factor for the occurrence of pulmonary TB in patients who had a normal chest radiograph. (hazard ratio, 9.079; 95\% CI, $1.012-81.431 ; \mathrm{P}=.049){ }^{22}$ There are many mechanisms by which steroids can increase the risk of tuberculosis. Steroids have profound effects on the cellular immune response. Glucocorticoids inhibit the lymphokine effect and monocyte chemotaxis and also block Fc receptor binding and function. ${ }^{23-25}$ Glucocorticoids decreases the number of peripheral blood monocytes as well as monocyte functions it leads to decreased bactericidal activity and production of interleukin-1 and TNF- $\alpha .{ }^{26}$ Glucocorticoids also inhibit $\mathrm{T}$ cell activation, leading to reduced proliferative responses and cytokine production, and they also induce a redistribution of lymphocytes (predominantly $\mathrm{T}$ cells) out of the circulation, leading to peripheral lymphocytopenia. ${ }^{27}$ These various effects of glucocorticoids on the cellular immune system may play a significant role in predisposing to tuberculosis infection.

\section{CONCLUSION}

All chronic ashamatic patients should be screened for AFB by Zn stain.

\section{REFERENCES}

1. Saxena S. Dayal V. Emergency Enviornment. Monitor 13. 93-102.

2. WHO Global Tuberculosis Report, 2018. Available from http://www.who.int/tb/publications/global_report/en/

3. Lozano R, Naghavi M, Foreman K, Lim S, Shibuya K, Aboyans V, et al.. Global and regional mortality from 235 causes of death for 20 age groups in 1990 and 2010: A systematic analysis for the Global Burden of Disease Study 2010. Lancet. 2012;380:2095-128.

4. Snider GL, Doctor L, Demas TA, Shaw AR. Obstructive airway disease in patients with treated pulmonary tuberculosis. Am Rev Respir Dis 1971;103:625-40.

5. Jain NK, Thakkar MS, Jain N, Rohan KA, Sharma M. Chronic obstructive pulmonary disease: Does gender really matter? Lung India 2011;28:258-62.

6. Verma SK, Kumar S, Narayan K, Sodhi R. Post tubercular obstructive airway impairment. Indian J Allergy Asthma Immunol 2009;23:95-9.

7. Zakaria M, Moussa H. Chronic obstructive pulmonary disease in treated pulmonary tuberculosis patients. Egypt J Bronchol 2015;9:10-3.

8. Lee CH, Lee MC, Star CC, Lim CS, Wang JY, Lee LN, et al. . Risk factors for pulmonary tuberculosis in patients with chronic obstructive airway disease in Taiwan: A nationwide cohort study. BMC Infect Dis 2013;13:194-6.

9. Aktogu S, Yorgancioglu A, Cirak K, Köse T, Dereli SM. Clinical spectrum of pulmonary and pleural tuberculosis: A report of 5,480 cases. Eur Respir J 1996;9:2031-5.

10. Didilescu C, Ibraim E, Plopeanu D. A study of the risk factors for relapse in pulmonary tuberculosis patients and the results of the re-treatment. Pneumologia 2000;49:247-52.

11. Wang JY, Lee LN, Hsueh PR. Factors changing the manifestation of pulmonary tuberculosis. Int $\mathrm{J}$ Tuberc Lung Dis 2005;9:777-83.

12. Rizvi N, Shah RH, Inayat N, Hussain N. Differences in clinical presentation of pulmonary tuberculosis in association with age. J Pak Med Assoc 2003;53:321-4.

13. Yakar HI, Gunen H, Pehlivan E, Aydogan S. The role of tuberculosis in COPD. Int J Chron Obstruct Pulmon Dis 2017;12:323-9.

14. Shprykov AS, Zhadnov VZ. Effects of tobacco smoking on the course of infiltrative pulmonary tuberculosis and effectiveness of its treatment. Probl Tuberk 1994;5;26-7.

15. Leung CC, Yew WW, Chan CK, Tam CM, Lam CW, Chang KC, et al.. Smoking and tuberculosis in Hong Kong. Int J Tuberc Lung Dis 2003;7:980-6

16. Smit KR. National Burden of disease in India from indoor air pollution. 2000. Proc Natl Acad Sci USA. Nov 21, 97(24). 13286-93.

17. Popescu C, Gheorghiu T, Russu R, Sepeanu S. Asthma and tuberculosis (considerations based on hospital case studies). Rev Ig Bacteriol Virusol Parazitol Epidemiol Pneumoftiziol. 1978;27:23-8.

18. Davies PD, Yew WW, Ganguly D, Davidow AL, Reichman LB, Dheda K, et al.. Smoking and tuberculosis: The epidemiological association and immunopathogenesis. Trans R Soc Trop Med Hyg 2006;100:291-8.

19. Bates MN, Khalakdina A, Pai M, Chang L, Lessa F, Smith KR. Risk of tuberculosis from exposure to tobacco smoke: A systematic review and meta-analysis. Arch Intern Med 2007;167:335-42.

20. Arcavi L, Benowitz NL. Cigarette smoking and infection. Arch Intern Med 2004;164:2206-16.

21. Pai M, Mohan A, Dheda K, Leung CC, Yew WW, Christopher DJ, et al.. Lethal interaction: The colliding 
epidemics of tobacco and tuberculosis. Expert Rev Anti Infect Ther 2007;5:385-91.

22. Jung-Hyun Kim MD, Soo Park MD Kyung-Ho KimMD Hye-Cheo 1Jeong MD Eun-Kyung Kim MD Hyun Lee MD. Inhaled Corticosteroid Is Associated With an Increased Risk of TB in Patients With COPD. CHEST. Volume 143, Issue 4, April 2013, Pages 1018-1024

23. Orme IM, Andersen P, Boom WH. T cell response to Mycobacterium tuberculosis. J Infect Dis 1993;167:148197.
24. Balow JE, Rosenthal AS. Glucocorticoid suppression of macrophage migration inhibitory factor. J Exp Med 1973;137: 1031-41.

25. Rinehart JJ, Sagone AL, Balcerzak SP, Ackerman GA, LoBuglio AF. Effects of corticosteroid therapy on human monocyte function. N Engl J Med 1975;292:236 - 41.

26. Segal BH, Sneller MC. Infectious complications of immunosuppressive therapy in patients with rheumatic diseases. Rheum Dis Clin North Am 1997;23:219 -37. Fauci AS, Dale DC, Balow JE. Glucocorticosteroid therapy: mechanisms of action and clinical considerations. Ann Intern Med 1976;84:304.

\section{Source of Support: None Declared \\ Conflict of Interest: None Declared}

\section{Policy for Articles with Open Access:}

Authors who publish with MedPulse International Journal of Microbiology (Print ISSN: 2550-7648) (Online ISSN: 2636-4646) agree to the following terms: Authors retain copyright and grant the journal right of first publication with the work simultaneously licensed under a Creative Commons Attribution License that allows others to share the work with an acknowledgement of the work's authorship and initial publication in this journal.

Authors are permitted and encouraged to post links to their work online (e.g., in institutional repositories or on their website) prior to and during the submission process, as it can lead to productive exchanges, as well as earlier and greater citation of published work. 